\title{
SIMULATION FOR IMPROVING THE PERFORMANCE OF SMALL AND MEDIUM SIZED ENTERPRISES
}

\author{
Dragic, M. \& Sorak, M. \\ University of Banja Luka, Faculty of Technology, Stepe Stepanovica 73, 78000 Banja Luka, \\ Bosnia and Herzegovina \\ E-Mail: miroslav.dragic@unibl.rs,milos.sorak@unibl.rs
}

\begin{abstract}
The success of small and medium enterprises to adapt to constant changes in the environment largely depends on the different strategies and management decisions taken by managers at the operational level. This paper is searching for a tool that would allow managers at all levels to consider the effects of their decisions on the success of the enterprise as a whole. In this sense, the application of system dynamics developed one modular simulation model of business processes of SMEs. Developed model recognizes the specificities of SMEs, such as a large range of products, the use of a wide variety of materials, production in small batches and requests for reduction of lead time (Lead Time). The effects of various strategies and management decisions can be observed by monitoring the dependence of performance measures of simulated process on values of model parameters. Through four experiments the effects of changes in inventory management policies, the availability and size of the lot were simulated. The results of experiments showed that the variation of the model parameters should be oriented simultaneously towards several of the aforementioned directions.

(Received in September 2015, accepted in April 2016. This paper was with the authors 4 months for 1 revision.)
\end{abstract}

Key Words: Simulation, Optimization, SMEs, Performance

\section{INTRODUCTION}

Markets at which many of nowadays small and medium enterprises operate are characterized by fast changing needs and expectations of customers. Intense competition has forced manufacturers to deliver products exclusively constructed with a strong correlation with users. To meet the needs of today's consumers, manufacturers need to continually develop new products and increase the diversity of existing products. In addition, manufacturers are constantly looking for ways to shorten the time between customer order and product delivery $[1,2]$. Changing customer requirements and demands for shortening the time between order and delivery require fundamental changes in planning process and provision of material for production.

Standard approaches to the production preparation process, based on static spread sheets plan, are not able to support the operational production planning in today's dynamic and uncertain environment. Due to this, there was the need for development of new tools that could be used to support decisions in daily production planning and inventory management [2-6]. The operative production planning becomes a complex process closely associated with variations in the parameters of the preparation and production. This primarily refers to the changing needs of customers, the inability to influence the parameters of the production process (machine failure, justified and unjustified absences of employees), uncertainty of the procurement process, deficiencies in the documentation and the like [2,7]. For these very reasons, manufacturing enterprises often use ERP (Enterprise Resource Planning) system to schedule and manage resources uniformly in order to enhance competitive advantage, efficiency and performance of business process. Usually the planning systems of ERP lack an integrated overall optimization mechanism, so the production planning, the material requirements planning, the capacity requirements planning and other plans of the planning system need to be calculated separately, and the coordination of multi-level plans is 
completed manually [6]. However synergistic effect of a whole depends heavily on the chosen strategy and managerial decisions made by the managers at the operational level during adjustment of work processes. Taking the above mentioned problem into account, a growing number of researchers have recently been asking questions and searching for a solution on how chosen strategies and managerial decisions made by the managers may contribute to enhancement of effectiveness and efficiency of the entire enterprise [2].

In this respect, a lot of papers proposes methods of improving the coordination, methods of optimizing the process route [8,9], production lot size [10] and lead time in order to optimize the planning [1,4]. Nevertheless these researches only consider the local optimization or improvement of system. Based on this, some researches propose integrated production planning models as methods to solve the problem of simultaneous optimization of different plans in enterprises. The paper [6] proposes a multi-objective optimization model of integrated production planning. Production plan under this model, besides materials and production capacity, also considers performance objectives of manufacturing process. Paper [11] studies the optimal control of and interaction between two types of flexibility: process flexibility and inventory flexibility. This paper demonstrates impact of system parameters on the value of process flexibility and inventory flexibility via a comprehensive numerical study using the method of product substitution. Many studies recognize the disadvantages of the existing systems, but generally they are focused on partial improvement or optimization of specific individual processes, as to increase the usability only at a certain level $[4,5,12]$.

Since real processes in small and medium-sized enterprises encompass a very large number of interrelated variables, their modelling requires a lot of experience and use of mathematical tools. Modern research in the field of computer modelling and simulation are in constant search for new and better approaches for the specification and implementation of simulation models in manufacturing systems. Taking the above mentioned problem into account, this paper is searching for a solution on how chosen strategies and managerial decisions made by the managers at the operational level may affect the overall performance of the enterprise as a whole. The model for simulation processes used in this research is built by using system dynamics method. The effects of applying the model to increase the efficiency and effectiveness of the simulated systems will be monitored through performance measures, i.e. by monitoring performance measures depending on the process of simulated values of the model parameters. Process performances which have to be monitored are performance for the delivery, capacity utilization, inventory turnover, and others.

\section{DEVELOPMENT OF MODEL FOR SIMULATION}

The notion of simulation, in general, involves a number of activities related to the experimental determination of the effects that occur in the system, process or model which imitates them. Experimenting on the simulation model, as experimenting with real objects, for various reasons is not always possible, leads to information about the behaviour of the elements of the real system [13-15]. In this paper we propose a modular system dynamics model of integrated business processes. It's a method for continuous system simulation with feedback, i.e. system in which individual elements can affect themselves through a chain of cause and effect $[13,16-18]$. The general process of simulation, which is also accepted in this work, basically involves the processes of building simulation models, planning and execution of simulation experiment and analyses the results and draws conclusions $[2,4,14,19]$.

A modular approach has been applied to building the simulation models for the need of the simulation process flows in small and medium-sized enterprises. This approach involves building a model from discrete units (modules), where each unit has its own objective, decision rules and performance measures. Simplified description of each module, easier 
monitoring of the process and results of the simulation process and eventually the possibility of modular construction of the simulation program represent the main advantages to this approach [2].

Small businesses are more flexible, compared to big ones, and have the ability to quickly adapt to constant change, but their main problem is the lack of resources (financial resources, lack of modern equipment, knowledge and the like). The paper [2] pointed out that these conditions impose some specific requirements for the simulation model that are reflected in the necessity for recognition of different trends of customer demands and continuous monitoring of raw materials supply, unfinished and finished products. At the same time, developed model must satisfy the specifics of SME production activities such as the large range of products, using a number of various materials, preparation and execution of the production process in small batches and constant requests to reduce the lead time.

In this research, for the need of the simulation process flows, a modular approach has been applied to building of the simulation models. Modules of a proposed model for the processes simulation in small and medium-sized enterprises, with the purpose of each module, are given in Fig. 1.

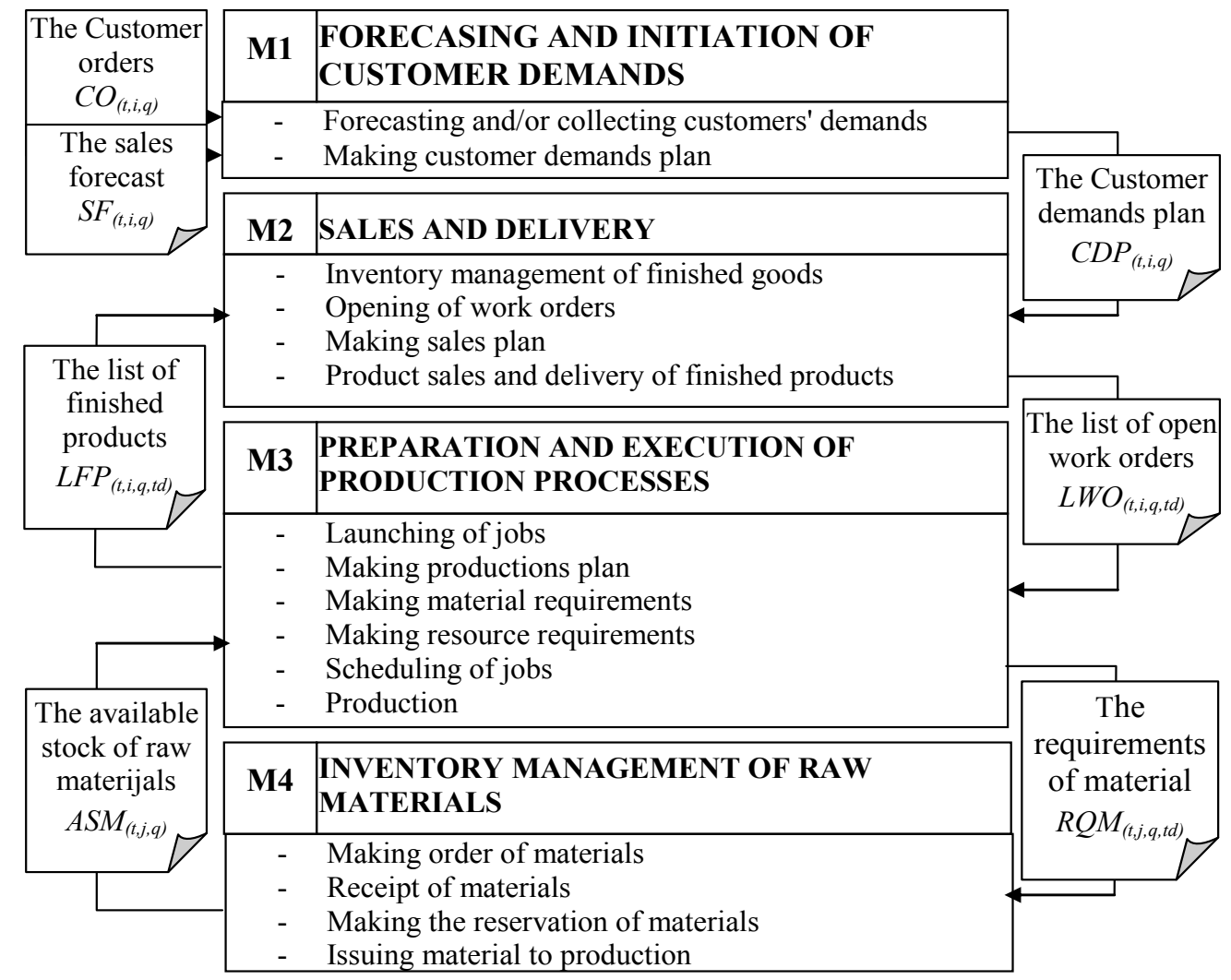

Figure 1: Integrated simulation model.

The basic logic of the developed system dynamics simulation model is described below. It shows the elements and equations of the model, which are the equivalent of behaviour of the real system. Since the subject of research is the process of the operational preparation of small and medium-sized enterprises, the detailed mathematics description is given for the processes of planning of production and management of materials inventory. By performing simulations under different conditions (changing model parameters) performance measures of simulated processes can be monitored depending on the model parameters' value. The following performances of the process are chosen to be followed: delivery performance, capacity utilization and inventory turnover (Table I, II and III) [2, 6, 20-22]. 


\subsection{Module M1 - Forecasting and initiation of customer demands}

The intensity and frequency of changes in the business environment imposed the need for integration of model for the evaluation of demand with the dynamics model of the system behaviour. As a basis for defining the parameters of this module sales data in the previous period, sales forecast contracts and plans can be used. Based on these data, for the period covered by simulation, this module simulates the arrival of customer demands (The Customer Demands Plan - CDP). It is expressed as a function of the order time $(t)$, type of product $(i)$ and the order quantity $(q)$. Taking into account the specificities of small and medium-sized enterprises, the module supports a variety of different types of flow of customer demands arrival, as well as variations in these flows.

\subsection{Module M2 - Sales and delivery}

This module monitors the reception and processing of customer requirements. Assuming that the requirements are arriving according to the rules defined in the previous module, the goal is to find a model to satisfy the demands of customers with a minimum level of stocks of finished products (Table I).

Table I: Performance and management objectives.

\begin{tabular}{|c|l|l|}
\hline Goal & Name & Definition \\
\hline$\uparrow$ & $\begin{array}{l}\text { Fulfilment of orders from } \\
\text { existing stocks }\end{array}$ & $\begin{array}{l}\text { Percentage of the amount of goods that customers request } \\
\text { and that can be met with existing supplies }\end{array}$ \\
\hline$\uparrow$ & Timeliness of delivery & $\begin{array}{l}\text { The percentage of orders that are met before or as } \\
\text { scheduled / promised delivery date }\end{array}$ \\
\hline$\uparrow$ & The value of executed orders & The total value of orders received in the relevant period \\
\hline$\downarrow$ & $\begin{array}{l}\text { The average level of finished } \\
\text { goods supply }\end{array}$ & The average value of finished goods supply over time \\
\hline
\end{tabular}

Customer demands arrive in unequal intervals with variations in the quantity and time of delivery. From the standpoint of processing the demands, module supports two basic options for meeting the orders: Make-to-Order (MTO) and Make-to-Stock (MTS).

In the first case the products are delivered directly from the warehouse of finished products. If there is not sufficient quantity in stock, the request is recorded as unrealized customer order, and its implementation is carried out after refill of stock in the warehouse. Adjustment of stocks of finished products is carried out using defined safety and maximum quantities. The system creates a work order for replenishment when the inventory level falls to a safety level.

In the second case, the request shall be recorded in the list of unimplemented demands, and then a work order is opened. Opening a work order is not possible until the development of the necessary technical documentation is finished. The time required for preparation of technical documentation varies from case to case. When production of the ordered products is completed, they will be delivered to customers.

\subsection{Module M3 - Preparation and execution of work processes}

Assuming that production process is organized as a process focused and that a batch methods is used (each batch goes through one stage of the production process before moving onto next stage), the module follows the course from the opening of the task to delivery of finished goods to the warehouse. The ultimate goal is to increase capacity utilization while reducing the level of unfinished production, so the performance regarding capacity utilization and the 
level of unfinished production are imposed as optimization criteria for simulated processes (Table II).

Table II: Performance and management objectives.

\begin{tabular}{|c|l|l|}
\hline Goal & Performance & Definition \\
\hline$\uparrow$ & Capacity utilization & The relationship between the required and available capacity \\
\hline$\downarrow$ & The flow coefficient & $\begin{array}{l}\text { Dimensionless number that shows the actual production cycle is } \\
\text { greater than the theoretical production cycle in ordinal way switch } \\
\text { series from one operation the other operation }\end{array}$ \\
\hline$\downarrow$ & $\begin{array}{l}\text { The average level } \\
\text { of work in progress }\end{array}$ & The average value of work in progress \\
\hline
\end{tabular}

Through the list of open work orders module M3 is associated with the module M2, and through the materials requisitions with module M4 simulation model. From the list of open work orders (generated in the module M2) the duties are taken over and their launch is carried out into the production process. The launch of its operations is running late after the process of job orders for the period necessary for the development and preparation. During the launch of operations in production a checking of material availability is done and reservation of the material needed to make batches of finished product (making requisitions based on the norms of material and batch size). For each launched work order definitions are provided for the start and end of each operation. They shall contain the dates of the production plan. The data on operations (list of operations) and data on available resources are used as a basis for the development of term production plan. The capacity capturing, the movement of jobs from one to another position, and delivery of finished goods to the warehouse are all done according to the adopted term production plan. The logic of the built module is shown in Fig. 2 (created in the Powersim Studio 10 Express software, available at http://www.powersim.com/).



Figure 2: Flow diagram for the module M3 - Preparation and execution of work production processes.

Parameters from other modules

M1: $C D P_{t, i}$ : the customer demand plan (product $i$ in quantity $q$ in phase $t$ );

M2: $O W O_{t, i}$ : the list of open work orders for product $i$ in phase $t$;

M4: $A S T_{t, j}$ : $\quad$ the available stock of material $j$ in phase $t$; 


\section{$\underline{\text { System parameters }}$}

$N M_{i, j}$ : the quantity of material $j$ needed for producing product $i$;

$N T_{i, r}: \quad$ the normative time of resource $r$ for product $i$;

$R C_{t, r}:$ the normal capacity of resource $r$ available in phase $t$;

$P D P_{i}$ : the product development period;

$T P P_{i}$ : the technical preparation period for product $i$;

$B S_{i}: \quad$ the batch size for producing product $i$;

Elements of the change in status

$L W O_{t, i}$ : the launching of work orders;

$M R Q_{t, j}:$ the material requirements;

$$
M R Q_{t, j}=L W O_{t, i} \cdot N M_{i, j}
$$

Start $\mathrm{SH}_{t, i, q}$ : the first starting point of scheduling;

$\operatorname{IF}\left(A S T_{t, j}>0\right.$, 'Launching of work orders', 0$)$

$S H_{t, r}$ : the scheduling of jobs at workplaces $r$ in phase $t$ (the FIFO algorithm is implemented);

$W P_{t, r}: \quad$ the working process on resource $r$ in phase $t$;

$$
W P_{t, r}=\operatorname{IF}\left(W H_{t, r}>0, S H_{t, r} / N T_{i, r}, 0\right)
$$

$F P_{t, i, q}:$ the final product entering;

\section{Elements of state}

$L L W_{t, i}:$ the launched work level for product $i$ in phase $t$;

$$
L L W_{t, i}=L L W_{t-1, i}+L W O_{t, i}
$$

$W H_{t, r}$ : the works on hold in front of resource $r$ in phase $t$;

$$
W H_{t, r}=W H_{t-1, r}+S H_{t, r}-W P_{t, r}
$$

$L W P_{t, i}:$ the work in progress level for product $i$ in phase $t$;

$$
L W P_{t, i}=L W P_{t-1, i}+S H_{t, r}-F P_{t, i}
$$

\subsection{Module M4 - Inventory management of raw materials}

This module monitors the processes related to providing materials necessary for the smooth running of the production process. Thereby it includes procedures such as inventory control, purchasing and receiving materials. It is assumed that the purchase lead time is known and there are always sufficient quantities of material. The material requirements are defined in the previous module. It is assumed that the materials required for the process of production are exempted once in the total amount when the production process starts. There is a tendency to maintain lower inventory levels while fulfilling the demand of the production process (Table III).

Table III: Performance and management objectives.

\begin{tabular}{|c|l|l|}
\hline Goal & Performance & Definition \\
\hline$\downarrow$ & $\begin{array}{l}\text { The average level of } \\
\text { stocks of materials }\end{array}$ & The average value of finished goods over a period \\
\hline$\uparrow$ & Inventory turnover & $\begin{array}{l}\text { The ratio of total material consumption in a certain period and } \\
\text { intermediate levels of inventories in the same time interval }\end{array}$ \\
\hline
\end{tabular}

From the angle of ordering process, inventory control method can be implemented via Fixed Size Ordering System (Q-system) or Fixed Period Ordering System (P-system). In the Fixed Size Ordering System, the maximum and minimum of standard inventory quantities are defined in advance, and the quantity of inventory gradually decreases, and when the number reaches ROP (Reorder Point Quantity), an order of EOQ (Economic Order Quantity) is placed. The Fixed Period Ordering System is an inventory control method where orders are periodically placed, but the order quantity is different every time and it depends of inventory quantity, released orders quantity and fluctuation in demand. 
In both cases, it should be noted that the available quantity of material is not only the amount of material that is physically located in the storehouse. Thus, the amount of material that is in the process of procurement (released order quantity) should be added to this amount and the amount of material necessary for the implementation of already launched work orders (reserved quantity of material) should be subtracted. The logic of the built module is shown in Fig. 3.

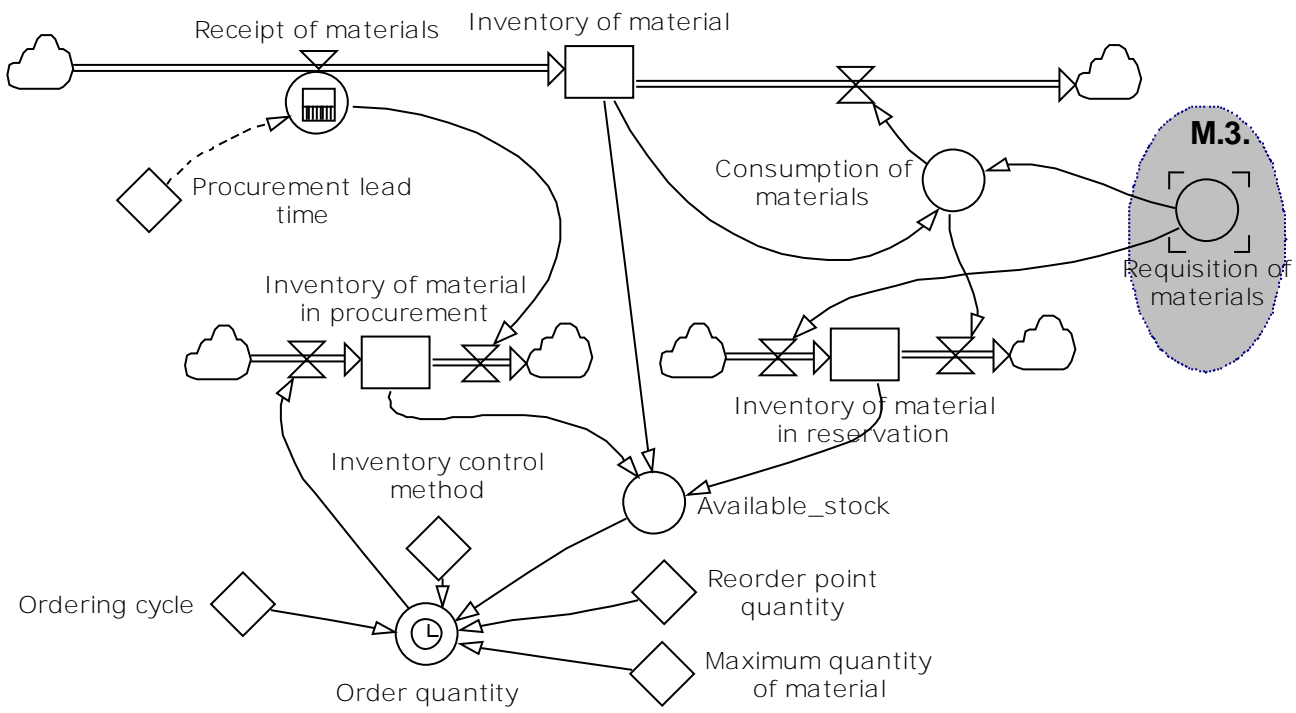

Figure 3: Flow diagram for the module M4 - Inventory management of raw materials.

Parameters from other modules

M3: $M R Q_{t, j}$ the material requirements of material $j$ in phase $t$;

System parameters

$I C M_{j}: \quad$ the inventory control method for material $j$;

$R O P_{j}: \quad$ the reorder point quantity of material $j$;

$\operatorname{Max} Q_{j}$ : the maximum quantity of material $j$;

$E O Q_{j}$ : the economic order quantity;

$E O Q_{j}=\operatorname{Max} Q_{j}-R O P_{j}$

$O C_{j}$ : $\quad$ the ordering cycle (time period between two orders) of material $j$;

$P R O_{j}$ : the procurement lead time (the time required for the realization of orders) of material $j$;

Elements of the change in status

$O Q_{t, j}: \quad$ the order quantity of material $j$ in phase $t$;

- For the fixed size ordering system

If $\left(A S_{t, j}<R O P_{j}\right)$ then $O Q_{t, j}=E O Q_{j}$ else $O Q_{t, j}=0$

- For fixed period ordering system

If $\left(t \bmod O C_{j}=0\right)$ then $O Q_{t, j}=\operatorname{Max} Q_{j}-A S T_{t, j}$ else $O Q_{t, j}=0$

$C M_{t, j}: \quad$ the consumption of materials $j$ in phase $t$;

$R M_{t, j}: \quad$ the receipt of materials $j$ in phase $t$;

$A S T_{t, j}: \quad$ the available stock of material $j$ in phase $t$;

$A S T_{t, j}=I M_{t, j}+I M P R_{t, j}-I M R_{t, j}$

Elements of state

$I M_{t, j}: \quad$ the inventory of material $j$ in phase $t$;

$I M_{t, j}=I M_{t-1, j}+R M_{t, j}-C M_{t, j}$

$I M P R_{t, j}$ : the inventory material in procurement in phase $t$;

$I M P R_{t, j}=I M P R_{t-1, j}+O Q_{t, j}-R M_{t, j}$

$I M R_{t, j}:$ the inventory material in reservation in phase $t$;

$$
I M R_{t, j}=I M R_{t-1, j}+M R Q_{t, j}+C M_{t, j}
$$




\subsection{The possibility of applying developed model}

Based on the above analysis of this model, one can notice a big interest in the supply chain in the planning, preparation and execution of the manufacturing process. The reasons for this should be sought in the fact that the production process is characterized by delays in production, lines in front of workplaces, lack of materials, and the like. Most of these problems have a major impact on the level of inventory in storehouse of raw materials and finished products.

In most cases, the above problems have significant impact on the process of operative preparation of production because there is no clear knowledge of their impact on the overall performance of the enterprises. The reasons are usually as follows:

- There is no standardized methodology for planning various options and / or

- Not enough time to explore different options during operational planning.

It is for these reasons that the developed model allows consideration of different options when choosing the optimal solution for a given situation. Thus, in the operational planning phase the current performance of the process can be monitored, such as the level of inventories in storehouses, the degree of capacity utilization, setbacks and the like. By performing simulations for a certain period of time and under certain conditions (adjusting process parameters) the future behaviour of the process can be predicted shown through the expected performance of the process (Table I, II and III). These performances are compared to planned performances, and if necessary, corrective actions are initiated (by changing the parameters of the process). The effectiveness of corrective actions can be predicted by performing simulation under the new conditions. The experiment needs to show how such changes affect other measures of business performance.

\section{CASE AND SIMULATION ANALYSIS}

In this research, we have used Powersim Studio 10 Express software to describe logic of model, and our own software to complete the model simulation and analysis. Powersim Studio is a fully-featured simulation model development environment. However, due to the complexity of the problem, in our case, we have developed our own software in the Visual Basic environment. The software was primarily developed for previous research [22] and for the purposes of this research it has been upgraded. This software fully supports the developed system dynamics simulation model, and allows us to perform simulations through a series of discrete events. The user interface allows the defining of system elements (production program, demand and demand forecast, list and quantity of raw materials, normative of raw materials, required and installed capacities, initial conditions, etc.) and elements of the simulation experiment (period of the simulation, simulation step, batch size, inventory management policy etc.). ODBC (Open Database Connectivity) interface enables data exchange with MS Access, MS SQL Server and PostgreSQL databases. This provides partial integration of model with existing information systems of the enterprise. The software automatically calculates the defined performance and results displayed through tables and graphics.

This paper describes a case study concerning the application of simulation in optimization of a small enterprise. The enterprise has defined production program, which includes about 10 product families and more product types by each family and it uses two order fulfilment options: Make-to-Order (MTO) and Make-to-Stock (MTS). There are 28 workers of different professions. In order to simplify the process of analysis, the product range, number of raw materials and recourses was reduced. So we have 5 kinds of products, 32 kinds of raw material, 9 kinds of recourses (16 units) and 9 phases of production. The basic data is shown in Tables IV-VII. 
Table IV: Reduced product range with the demand model parameters.

\begin{tabular}{|c|c|c|c|c|c|c|c|c|c|c|c|c|}
\hline \multicolumn{3}{|c|}{ PRODUCT: } & \multirow[b]{3}{*}{ 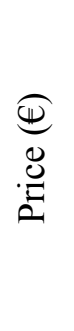 } & \multirow{3}{*}{ 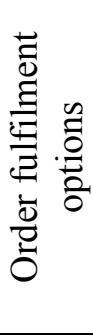 } & \multirow{3}{*}{ 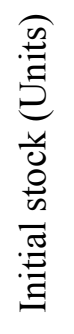 } & \multirow{3}{*}{ 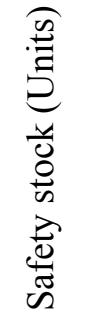 } & \multirow{3}{*}{ 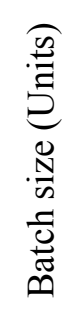 } & \multirow{3}{*}{ 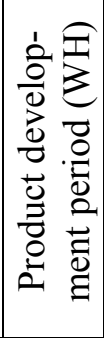 } & \multirow{3}{*}{ 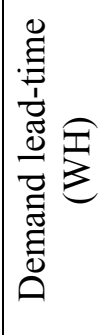 } & \multirow{3}{*}{ 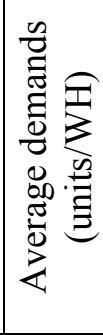 } & \multirow{3}{*}{ 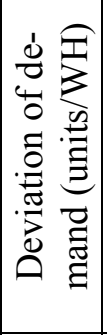 } & \multirow{3}{*}{ 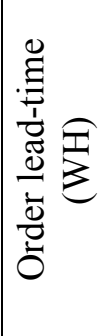 } \\
\hline & & $W H$ - the working hour & & & & & & & & & & \\
\hline$i$ & ID & Name & & & & & & & & & & \\
\hline 1 & 400000 & Pallet she & 160 & MTS & 60 & 50 & 100 & 0 & 8 & 2 & 2 & 0 \\
\hline 2 & 410000 & Mailbo & 30 & MTS & 240 & 200 & 200 & 0 & 8 & 16 & 8 & 0 \\
\hline 3 & 420000 & El. distribution cab. & 600 & MTO & 0 & 0 & - & 40 & 8 & 4 & 4 & 120 \\
\hline 4 & 440000 & High-rack storage & 130 & MTO & 0 & 0 & - & 16 & 8 & 12 & 6 & 64 \\
\hline 5 & 490000 & Distribution board & 12 & MTS & 100 & 50 & 200 & 0 & 1 & 5 & 5 & 0 \\
\hline
\end{tabular}

Table V: Reduced list of material with the corresponding parameters of the model.

\begin{tabular}{|c|c|c|c|c|c|c|c|c|}
\hline \multicolumn{3}{|c|}{ MATERIALS: } & \multirow{2}{*}{$\begin{array}{l}\mathbb{1} \\
0 \\
0 \\
0 \\
0\end{array}$} & \multirow{2}{*}{ 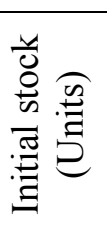 } & \multirow{2}{*}{ 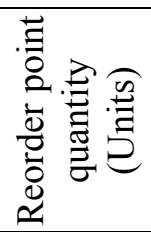 } & \multirow{2}{*}{ 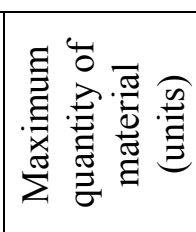 } & \multirow{2}{*}{ 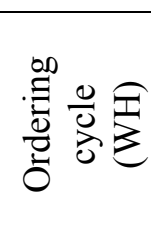 } & \multirow{2}{*}{ 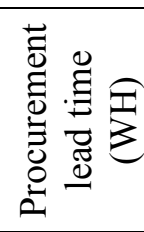 } \\
\hline$j$ & ID & Name & & & & & & \\
\hline 1 & 200005 & Sheet $0.6 \mathrm{~mm}$ & 10 & 220 & 200 & 400 & 0 & 18 \\
\hline 2 & 200011 & Sheet $1.0 \mathrm{~mm}$ & 16 & 120 & 100 & 300 & 0 & 18 \\
\hline 3 & 200080 & Silencer F-40XN & 4 & 1100 & 400 & 2800 & 0 & 8 \\
\hline & & & & & & & . & \\
\hline 32 & 201196 & Cable $\phi 3 \mathrm{~mm}$ & 28 & 0 & 1 & 10 & 0 & 8 \\
\hline
\end{tabular}

Table VI: Normative of raw materials.

\begin{tabular}{|c|c|c|c|c|c|c|c|c|}
\hline \multirow{2}{*}{\multicolumn{2}{|c|}{$\frac{j}{\text { Material ID }}$}} & 1 & 2 & 3 & 4 & $\ldots$ & 31 & 32 \\
\hline & & 200005 & 200011 & 200080 & 200107 & $\ldots$ & 200990 & 201196 \\
\hline$i$ & Product ID & \multicolumn{7}{|c|}{ tent } \\
\hline 1 & 400000 & 0.85 & 0.43 & 2.00 & 4.00 & $\ldots$ & & 0.01 \\
\hline 2 & 410000 & & 0.40 & & & $\ldots$ & & 0.01 \\
\hline 3 & 420000 & 3.67 & 0.17 & & & $\ldots$ & 8.00 & \\
\hline 4 & 440000 & & 3.50 & & & $\ldots$ & & \\
\hline 5 & 490000 & & 0.12 & & & $\ldots$ & & \\
\hline
\end{tabular}

Table VII: Capacity required per product unit.

\begin{tabular}{|c|c|c|c|c|c|c|c|c|c|c|c|}
\hline & $r$ & 1,2 & 3 & 4 & 5,6 & 7,8 & 9,10 & 11,12 & 13,14 & 15,16 & \multirow{4}{*}{ 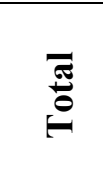 } \\
\hline & Recourse & $\mathrm{HMZ}$ & EUR & MHP & APP & $\mathrm{CO} 2$ & BRU & LAK & $\mathrm{MON}$ & MONE & \\
\hline \multicolumn{2}{|c|}{ Operation No. } & 10 & 20 & 30 & 40 & 50 & 60 & 70 & 80 & 90 & \\
\hline \multicolumn{2}{|r|}{ Setup time } & $15 \mathrm{~min}$ & $20 \mathrm{~min}$ & $20 \mathrm{~min}$ & $15 \mathrm{~min}$ & $15 \mathrm{~min}$ & $10 \mathrm{~min}$ & $30 \mathrm{~min}$ & $20 \mathrm{~min}$ & $30 \mathrm{~min}$ & \\
\hline$i$ & ID & \multicolumn{10}{|c|}{ Run time (min) } \\
\hline 1 & 400000 & 3.33 & 2.83 & 4.00 & 7.50 & 4.00 & 4.00 & 4.00 & 10.00 & 8.00 & 47.66 \\
\hline 2 & 410000 & 1.50 & 1.50 & 2.50 & 3.50 & 6.00 & 2.00 & 3.00 & 5.00 & 0.00 & 25.00 \\
\hline 3 & 420000 & 10.83 & 0.72 & 7.00 & 18.00 & 20.00 & 3.00 & 10.00 & 10.00 & 150.00 & 229.55 \\
\hline 4 & 440000 & 10.00 & 10.00 & 0.00 & 14.00 & 8.00 & 8.00 & 18.00 & 0.00 & 0.00 & 68.00 \\
\hline 5 & 490000 & 1.60 & 1.50 & 0.00 & 1.60 & 3.00 & 0.00 & 0.25 & 0.00 & 0.00 & 7.95 \\
\hline
\end{tabular}

In first stage we must define time parameters of the experiment. The period of one working hour $(1 \mathrm{WH})$ is adopted as the basic time unit (step of the simulation). The period of 
the simulation execution corresponds to the fourth quarter of fiscal 2014. If we assume that the enterprise operates five days a week, in this period there are 65 working days (with 8 $\mathrm{WH})$, the total time will be $520 \mathrm{WH}$.

Firstly, the experiment was conducted using the model parameters adopted from the real data of the simulated system. The behaviour of the simulated system can be represented by series of graphics, including changes in the level of material (Fig. 4.), finished goods (Fig. 5 a), work in progress (Fig. 5 b), and the occupancy rate (Table VIII) or even by monitoring performance measures (Table $\mathrm{X}$ ).

Table VIII: Term production plan (part).

\begin{tabular}{|c|c|c|c|c|c|c|c|c|c|c|c|c|}
\hline Reco & $\begin{array}{l}\text { Term unit } \\
\text { urse }\end{array}$ & 51 & 52 & 53 & 54 & 55 & 56 & 57 & 58 & 59 & 60 & $\begin{array}{r}\text { Utilization } \\
\% \\
\end{array}$ \\
\hline 1 & HMZ & $22 / 10$ & $22 / 10$ & $22 / 10$ & $22 / 10$ & $22 / 10$ & & $10 / 10$ & $10 / 10$ & & & $46.38 \%$ \\
\hline 2 & HMZ & $23 / 10$ & & & & & & $19 / 10$ & $19 / 10$ & $19 / 10$ & & $37.32 \%$ \\
\hline 3 & EUR & $17 / 20$ & $17 / 20$ & & & & $22 / 20$ & $22 / 20$ & $22 / 20$ & $22 / 20$ & $22 / 20$ & $57.49 \%$ \\
\hline 4 & MHP & $6 / 30$ & $23 / 20$ & $17 / 30$ & & & & & & $10 / 20$ & $10 / 30$ & $49.46 \%$ \\
\hline 5 & APP & & $6 / 40$ & $6 / 40$ & $17 / 40$ & $17 / 40$ & $17 / 40$ & & & & & $70.65 \%$ \\
\hline 6 & APP & $8 / 40$ & $8 / 40$ & $23 / 30$ & $23 / 40$ & & & & & & $19 / 20$ & $50.91 \%$ \\
\hline 7 & $\mathrm{CO} 2$ & $5 / 50$ & $5 / 50$ & $\overline{5 / 50}$ & $6 / 50$ & $6 / 50$ & & $17 / 50$ & $17 / 50$ & & & $71.56 \%$ \\
\hline 8 & $\mathrm{CO} 2$ & $15 / 50$ & $15 / 50$ & $8 / 50$ & $8 / 50$ & $8 / 50$ & $8 / 50$ & $8 / 50$ & $8 / 50$ & $8 / 50$ & $8 / 50$ & $59.06 \%$ \\
\hline 9 & BRU & & & & $5 / 60$ & $5 / 60$ & $5 / 60$ & $5 / 60$ & $5 / 60$ & $5 / 60$ & $5 / 60$ & $55.98 \%$ \\
\hline 10 & BRU & $12 / 50$ & $12 / 50$ & $12 / 50$ & $12 / 50$ & $12 / 60$ & $6 / 60$ & & & $17 / 60$ & $17 / 60$ & $32.07 \%$ \\
\hline 11 & LAK & $1 / 70$ & & $15 / 60$ & $15 / 60$ & $23 / 50$ & $12 / 70$ & $6 / 70$ & & & & $62.32 \%$ \\
\hline 12 & LAK & $11 / 70$ & $11 / 70$ & $11 / 70$ & $11 / 70$ & $11 / 70$ & $11 / 70$ & $23 / 70$ & & & & $29.35 \%$ \\
\hline 13 & MONT & & $1 / 80$ & $1 / 80$ & & & $23 / 60$ & $12 / 80$ & $6 / 80$ & $15 / 80$ & & $60.33 \%$ \\
\hline 14 & MONT & & & & & & & $11 / 80$ & $23 / 80$ & & & $23.02 \%$ \\
\hline 15 & MONTE & & & & & & . & & $12 / 90$ & $23 / 90$ & $15 / 90$ & $46.74 \%$ \\
\hline
\end{tabular}

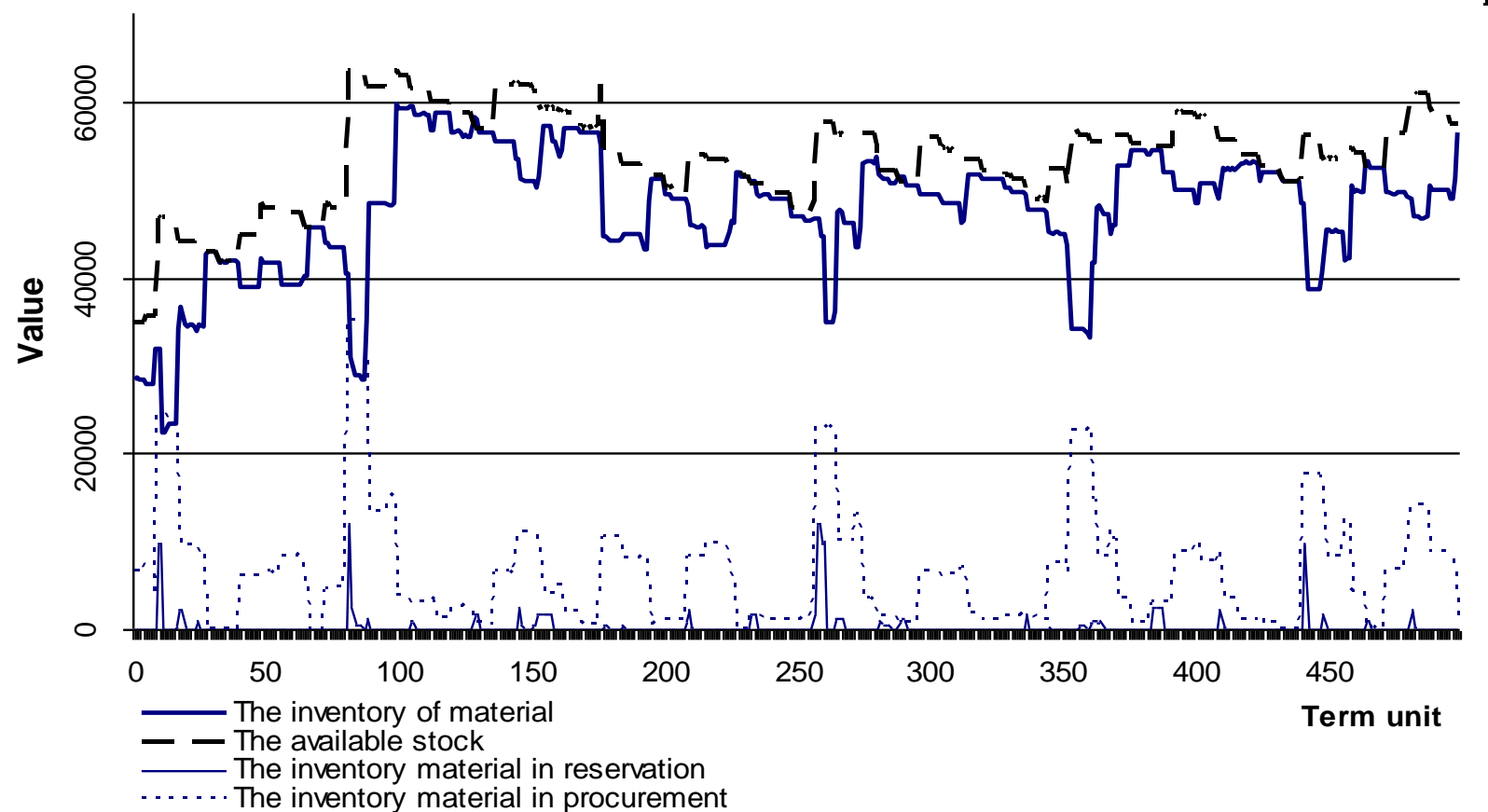

Figure 4: The level of inventories of raw materials. 


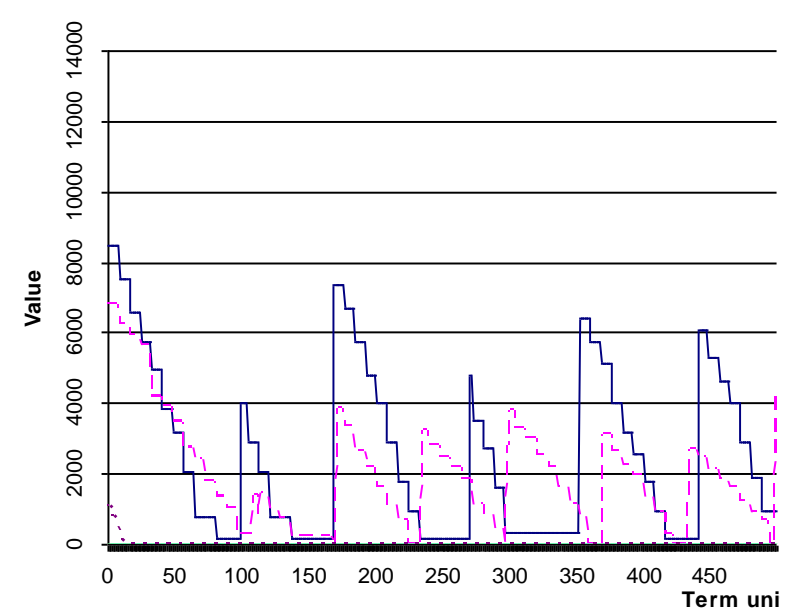

a) The level of finished goods

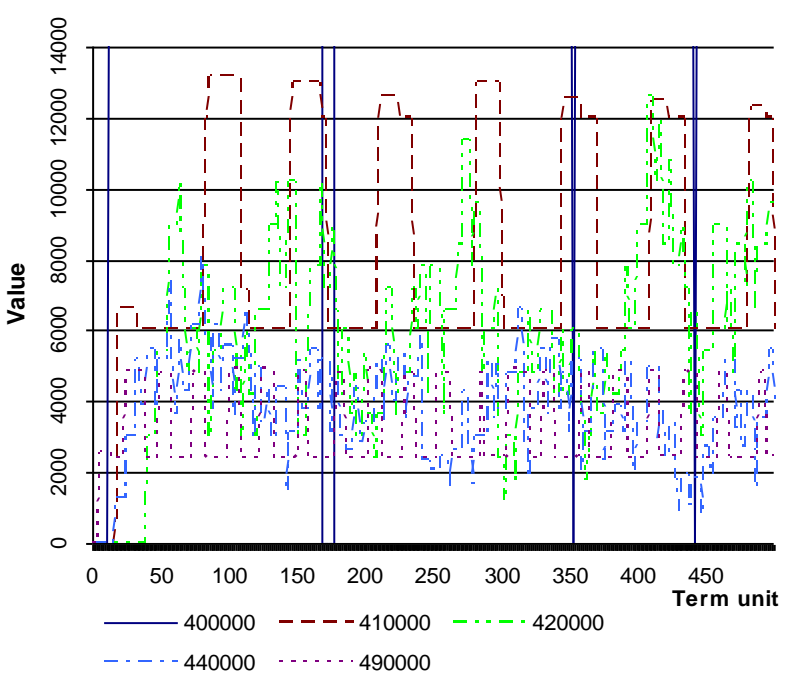

b) The level of work in progress

Figure 5: The level of products across the period.

Different variants of the experiment implementation are obtained by changing (to more or to less) the model parameters, i.e. by their variation aimed at direct improvement of one or more processes performance measures. The experiment needs to show how such changes affect other performance measures. Customer satisfaction is the key to continuing success of the enterprise, so below, we shall look into the effects of the three different strategies in order to improve customer service. The adopted plan for conducting multiple experiments with the plan of model parameter variations is given in Table IX.

Table IX: Simulation experiment plan.

\begin{tabular}{|l|l|}
\hline $\mathbf{I}$ & Basic variant of the experiment \\
\hline $\mathbf{I}$ & $\begin{array}{l}\text { Variant with an increased level of finished products in stock } \\
\text { The results shown in Fig. 5 a indicate the lack of stock of the product no. 490000, so we shall } \\
\text { increase the safety stock level and work order quantity. }\end{array}$ \\
\hline $\mathbf{I}$ & $\begin{array}{l}\text { Variant with increased available capacity } \\
\text { The introduction of new machines is primarily aimed at affecting reduction of the production } \\
\text { cycle and the level of work in process. Changes should be made to job groups that have the } \\
\text { highest capacity utilization like as HMZ, CO2, MONTE and BRU (see Table VIII). }\end{array}$ \\
\hline $\mathbf{s}$ & $\begin{array}{l}\text { Variant with decreased batch size } \\
\text { Decreasing the batch size aims to decrease the level of unfinished goods (Fig. } 5 \mathrm{~b} \text { ) and } \\
\text { consequently to increase the level of customer service. The batch size of product will be } \\
\text { decreased from 200 to 50 units. }\end{array}$ \\
\hline $\mathbf{x}$ & $\begin{array}{l}\text { Variant with combined action } \\
\text { Depending on the results of previous experiments, variations of the model parameters will be } \\
\text { focused on more of the above mentioned directions. }\end{array}$ \\
\hline
\end{tabular}

A comparative overview of the experiment results are shown in Table X.

By analysing the obtained results of experiment E1, it is possible to conclude that the increase in stock level of products leads to an increase in the level of customer services especially the fulfilment of orders from existing stock and timeliness of delivery. An undesirable increase in the level of work in process was expected.

Increase in available production capacity (E2) decreases their utilization with no significant (positive) effects on other performance measures. 
Table X: A comparative overview of the experiment results.

\begin{tabular}{|c|l|c|c|c|c|c|}
\hline \multicolumn{2}{|c|}{ Business performance measure } & E0 & E1 & E2 & E3 & E4 \\
\hline$\uparrow$ & Fulfilment of orders from existing stock & $7.52 \%$ & $12.89 \%$ & $7.50 \%$ & $20.61 \%$ & $22.00 \%$ \\
\hline$\uparrow$ & Timeliness of delivery & $31.69 \%$ & $50.34 \%$ & $31.41 \%$ & $67.35 \%$ & $75.86 \%$ \\
\hline$\uparrow$ & The value of realized orders & $403922 €$ & $415004 €$ & $402992 €$ & $455998 €$ & $467146 €$ \\
\hline$\downarrow$ & The average level of finished goods inventory & $4418 €$ & $4496 €$ & $4342 €$ & $12246 €$ & $12223 €$ \\
\hline$\uparrow$ & Capacity utilization & $53.43 \%$ & $54.06 \%$ & $44.71 \%$ & $57.24 \%$ & $69.44 \%$ \\
\hline$\downarrow$ & The flow coefficient & 1.33 & 1.29 & 1.32 & 1.61 & 1.81 \\
\hline$\downarrow$ & The average level of work in progress & $37459 €$ & $38975 €$ & $37534 €$ & $24887 €$ & $27139 €$ \\
\hline$\downarrow$ & The average level of materials in stock & $47520 €$ & $47361 €$ & $47420 €$ & $46930 €$ & $47270 €$ \\
\hline$\uparrow$ & Inventory turnover & 4.71 & 4.77 & 4.7 & 5.13 & 5.3 \\
\hline
\end{tabular}

Decreasing batch size in production (E3) entails a number of positive effects on performance measures (better customer service, better capacity utilization, lower level of work in progress and a better inventory turnover), along with somewhat poorer flow coefficient and increasing level of finished goods inventory.

A comparative overview of the experiment results show that it is not possible to find a set of model parameters that will improve all the performances without any negative effects. It is clear that variations of the model parameters should be focused on several of the above mentioned directions. In this regard the fourth experiment (E4) that combines the increased level of stocks of finished products (E1) with a reduced size of series (E3) was organized. This has proved to be the best solution because this combination achieved a very significant improvement in the level of service, capacity utilization levels and unfinished products. However the average level of finished product inventories increased by $176 \%$, which in practice may require an additional storage capacity (Fig. 6).

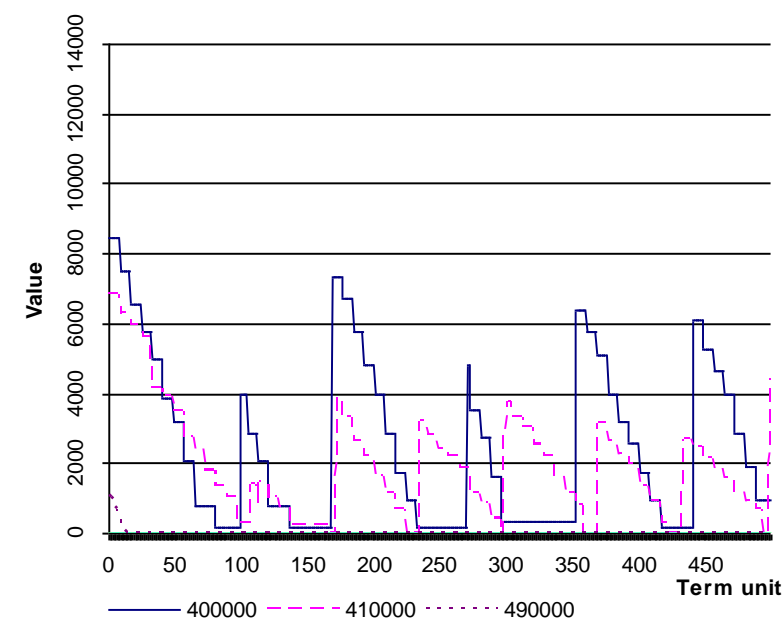

a) Basic variant of the experiment

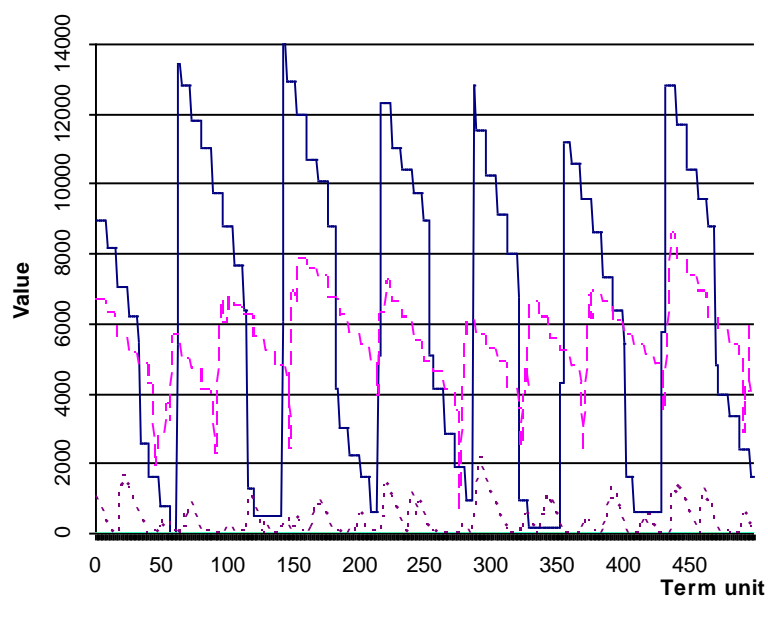

b) Combined variant of the experiment

Figure 6: Comparison of level of finished goods.

The optimal set of the model parameters should be obtained by combining the aforementioned experiments with a constant monitoring of the overall performance. However, the chosen parameters must be adapted to the enterprise policy and possibilities for organizing resources (equipment, human, financial, etc.). Therefore, Table X provides only guidelines for improving the overall performances of small and medium sized enterprises, in order to achieve, if not perfect, then at least acceptable level. 


\section{CONCLUSION}

Results of experiments showed that it is difficult for the management of small and mediumsized enterprises to find actions that will lead to improvement of certain performances of the enterprise without negative effects on the other performances. Significant improvements can be obtained only by coordinated changes aimed in several directions (policy changes in inventory management, increase / decrease of capacities, different models of launching operations in manufacturing, etc.). Therefore, coordination of management actions made by managers at various levels is imposed as a key issue in the business practices of SME in the field of production activity.

This work has demonstrated that a very simple dynamic simulation tool with a simple user interface can significantly improve the coordination process. Thus, by performing simulations of the model one can predict an enterprise's ability to cope with the changing environment. In addition, it is possible to predict the effects of running various actions in order to increase the ability of the enterprise to meet the requirements of customers. Depending on the time horizon, the developed model can be used for finding solutions for wide range of problems related to process management, starting with determining the type of production processing organization (long-term decision) up to observing the effects of changes in the work schedule in production (current decision).

\section{ACKNOWLEDGEMENT}

This research was supported by Ministry of Science and Technology of the Republic of Srpska under Grant No. 19/6-020/961-34/15.

\section{REFERENCES}

[1] Burnard, K.; Bhamra, R. (2011). Organisational resilience: development of a conceptual framework for organisational responses, International Journal of Production Research, Vol. 49, No. 18, 5581-5599, doi:10.1080/00207543.2011.563827

[2] Sorak, M.; Dragic, M. (2013). Supply chain management of small and medium-sized enterprises, Katalinic, B.; Tekic, Z. (Eds.), DAAAM International Scientific Book 2013, DAAAM International, Vienna, 951-968, doi:10.2507/daaam.scibook.2013.59

[3] Li, C.; Liu, F.; Cao, H.; Wang, Q. (2007). A stochastic dynamic programming based model for uncertain production planning of re-manufacturing system, International Journal of Production Research, Vol. 47, No. 13, 3657-3668, doi:10.1080/00207540701837029

[4] Jodlbauer, H.; Reitner, S. (2012). Material and capacity requirements planning with dynamic lead times, International Journal of Production Research, Vol. 50, No. 16, 4477-4492, doi: $10.1080 / 00207543.2011 .603707$

[5] Špicar, R. (2014). System dynamics archetypes in capacity planning, Procedia Engineering (24 $4^{\text {th }}$ DAAAM International Symposium on Intelligent Manufacturing and Automation), Vol. 69, 13501355, doi:10.1016/j.proeng.2014.03.128

[6] Wang, C.; Liu, X.-B.; Zhao, G.-Z.; Chin, K. O. (2014). Multi-objective integrated production planning model and simulation constrained doubly by resources and materials, International Journal of Simulation Modelling, Vol. 13, No. 2, 243-254, doi:10.2507/IJSIMM13(2)CO10

[7] Sawik, T. (2006). Hierarchical approach to production scheduling in make-to-order assembly, International Journal of Production Research, Vol. 44, No. 4, 801-830, doi:10.1080/ $\underline{00207540500340969}$

[8] Suliman, S. M. A.; Jawad, S. H. (2012). Optimization of preventive maintenance schedule and production lot size, International Journal of Production Economics, Vol. 137, No. 1, 19-28, doi: $\underline{10.1016 / j . i j p e .2012 .01 .006}$ 
[9] Jovanovic, J. R.; Milanovic, D. D.; Djukic, R. D. (2014). Manufacturing cycle time analysis and scheduling to optimize its duration, Strojniski vestnik - Journal of Mechanical Engineering, Vol. 60, No. 7-8, 512-524, doi:10.5545/sv-jme.2013.1523

[10] Zou, J.; Zhang, Y.; Miao, C. (2015). The single machine serial batch production scheduling with outsourcing allowed, Technical Gazette, Vol. 22, No. 2, 297-302, doi:10.17559/TV20150312154507

[11] Iravani, S. M. R.; Kolfal, B.; Van Oyen, M. P. (2014). Process flexibility and inventory flexibility via product substitution, Flexible Services and Manufacturing Journal, Vol. 26, No. 3, 320-343, doi:10.1007/s10696-012-9142-7

[12] Cheraghi, S. H.; Thirtha, M.; Krishnan, K. K. (2006). An optimization-based system for adaptive planning in a discrete part manufacturing environment, International Journal of Computer Integrated Manufacturing, Vol. 19, No. 2, 125-135, doi:10.1080/09511920500064730

[13] Özbayrak, M.; Papadopoulou, T. C.; Akgun, M. (2007). Systems dynamics modelling of a manufacturing supply chain system, Simulation Modelling Practice \& Theory, Vol. 15, No. 10, 1338-1355, doi:10.1016/j.simpat.2007.09.007

[14] Hall Marketing. Corporate Cartooning: The Art, Science and Craft of Computer Business Simulation Design, from http://www.simulations.co.uk/Corporate\%20Cartooning.htm, accessed on $25-07-2014$

[15] Tako, A. A.; Robinson, S. (2012). The application of discrete event simulation and system dynamics in the logistics and supply chain context, Decision Support Systems, Vol. 52, No. 4, 802-815, doi:10.1016/i.dss.2011.11.015

[16] Forrester, J. W. (1961). Industrial Dynamics, MIT Press, Cambridge, Massachusetts

[17] U.S. Department of Energy's. Introduction to System Dynamics (Authors: Radzicki, M. J.; Taylor, R. A.), from http://www.systemdynamics.org/DL-IntroSysDyn/, accessed on 26-08-2014

[18] Coyle, R. G. (1996). System dynamics modelling: A practical approach, $1^{\text {st }}$ ed., Chapman \& Hall/CRC, Boca Raton

[19] Min, H.; Zhou, G. (2002). Supply chain modelling: past, present and future, Computers \& Industrial Engineering, Vol. 43, No. 1-2, 231-249, doi:10.1016/S0360-8352(02)00066-9

[20] Vlajić.J.; Vidović, M.; Miljuš, M. (2005). Supply chains - defining and performances, The International Journal of Transport \& Logistics, Vol. 9, 85-113

[21] Feng, Y.; D'Amours, S.; Beauregard, R. (2010). Simulation and performance evaluation of partially and fully integrated sales and operations planning, International Journal of Production Research, Vol. 48, No.19, 5859-5883, doi:10.1080/00207540903232789

[22] Dragic, M. (2010). Supply Chain Optimization Using Simulation, Master Thesis, University of Banja Luka, Faculty of Mechanical Engineering, Banja Luka 